\title{
Prevention of wound infection: a new technique
}

\author{
Mahendra Kumar*, Preeti Pawar \\ Department of Obstetrics and Gynecology, Government Medical College Aurangabad, Maharashtra, India
}

Received: 07 July 2020

Accepted: 05 August 2020

\section{*Correspondence:}

Dr. Mahendra Kumar,

E-mail: mahendrakirankargmc85@gmail.com

Copyright: $\odot$ the author(s), publisher and licensee Medip Academy. This is an open-access article distributed under the terms of the Creative Commons Attribution Non-Commercial License, which permits unrestricted non-commercial use, distribution, and reproduction in any medium, provided the original work is properly cited.

\section{ABSTRACT}

Background: Caesarean delivery is a major obstetrical surgical procedure aiming to save the lives of mothers and fetuses. Caesarean sections have a 5 to 20 -fold greater chance of getting an infection compared with women who give birth vaginally. These infections can be in the organs within the pelvis, around the surgical incision. Microorganisms isolated from surgical site infection (SSI) were mostly from skin and vaginal flora. The most effective SSI prevention strategies involve a multi-faceted approach including protocols exercised before, during, and after surgery to reduce exposure and susceptibility to pathogens.

Methods: It was a case control study conducted in our hospital on caesarean patients. Total 240 patients were recruited for study, divided into cases (DDT group) and control (SDT group). Demographic data collected and follow till 30 days of surgery. SSIs patients identified and treated.

Results: Out of total 240 patients, mean age SDT, DDT and total patients were 28.46, 28.6 and 28.3 years respectively. Maximum numbers of cases were among multigravida (gravidity) and lower and lower-middle class (socioeconomic status). SSIs patients were seen mostly in SDT group, which was statistically significant. Among SSIs patient maximum numbers of patients were seen in age group of 18-22 years, primigravida and lower socioeconomic class. After their diagnosis most of the patients were treated with resuturing.

Conclusions: SSI is common complication after caesarean section; it can be prevented by increasing the hygienic condition in laboring patients. Authors newer method can be a future option for maintaining the intraoperative hygiene.

Keywords: Caesarean wound infection, Double drape technique, Drape, Surgical site infection, Wound infection

\section{INTRODUCTION}

Caesarean delivery is a major obstetrical surgical procedure aiming to save the lives of mothers and fetuses. ${ }^{1}$ The incidence of caesarean deliveries, both repeat and primary, has risen dramatically over the last few decades, with an estimated global number of 22.9 million caesarean deliveries in 2012. ${ }^{3,4}$ Caesarean wound infection is a major cause of prolonged hospital stay, high hospital bills, as well as other morbidities and mortality. ${ }^{5-}$ ${ }^{7}$ The incidence of wound infection has been shown to be influenced by the duration of labor prior to the caesarean section, prolonged period of rupture of membranes, postoperative anemia, skill of the surgeon, duration of operation and multiple vaginal examinations. ${ }^{8,9}$ Emergency caesarean section, booking status, and maternal age have been implicated by other researcher as significant factors influencing the incidence of wound infection. ${ }^{10}$ Women undergoing caesarean section have a 5 to 20 -fold greater chance of getting an infection compared with women who give birth vaginally. These infections can be in the organs within the pelvis, around the surgical incision and sometimes the urine. The infections can be serious, and very occasionally can lead to mother`s death.

The centers for disease control and prevention defines SSI as an infection occurring within 30 days from the 
operative procedure in the part of the body where the surgery took place. ${ }^{11}$ It divides SSIs into incisional SSI and organ/space SSI. Incisional SSI is further divided into superficial, involving the skin and subcutaneous tissue, and deep SSI, involving fascia and muscle layers. ${ }^{11}$ Surgical wounds can become infected by germs that are already on your skin that spread to the surgical wound, germs that are inside your body or from the organ on which the surgery was performed, germs that are in the environment around you such as infected surgical instruments or on the hands of the health care provider.

Most bacteria live on our skin, in the nasopharynx, gastrointestinal tract and other parts of the body with little potential for causing disease because of first line defence by the intact skin. The development of wound infection depends on the interplay of many factors that lead to a breakdown of the host protective layer- the skin, thus disturbing the protective functions of the layer, with introduction of many cell types into the wound to initiate host response. ${ }^{12}$ Infection of the wound is the successful invasion and proliferation by one or more species of microorganisms anywhere within the body's sterile tissues, sometimes resulting in pus formation. ${ }^{12,13}$

There are two mechanisms responsible for the development of post-caesarean wound infection; first, increased amniotic fluid and wound colonization by cervico-vaginal flora due to prolonged rupture of membranes and prolonged labour. The second mechanism involves increased exogenous bacterial contamination by skin flora due to breaks in sterile technique, especially with difficult surgeries, unbooked status and inadequate skin preparation with solutions contaminated with bacteria. ${ }^{14,15}$ Various Studies have shown that the isolated organisms from wound infection site following either emergency or elective caesarean sections are direct contamination from the skin or vagina flora and also nosocomial infections. ${ }^{16,17}$

Common offending organisms include Staphylococcus species, Enterococcus faecalis, Escherichia coli, Proteus mirabilis, and Pseudomonas species. Staphylococcus aureus is the most commonly isolated bacteria in wound infections following caesarean section. ${ }^{18}$ This organism causes serious infections and has been shown to be resistant to commonly available, cheap antibiotic like the penicillin. ${ }^{19}$ Other workers isolated more gram negative organisms such as E. coli, P. mirabilis, Pseudomonas and Klebsiella in caesarean section wound infections. ${ }^{20}$

The most effective SSI prevention strategies involve a multi-faceted approach including protocols exercised before, during, and after surgery to reduce exposure and susceptibility to pathogens. It include prophylactic antibiotic use (preoperative first generation cephalosporin and intravenous azithromycin), chlorhexidine skin preparation instead of iodine, hair removal using clippers instead of razors, vaginal cleansing by povidone-iodine, placental removal by traction of the umbilical cord instead of by manual removal, suture closure of subcutaneous tissue if the wound thickness is $>2 \mathrm{~cm}$, and skin closure with sutures instead of with staples. ${ }^{2,21-25}$

Sterile surgical drapes are used during surgery to prevent contact with unprepared surfaces and to maintain the sterility of environmental surfaces, equipment and the patient's surroundings. Similarly, sterile surgical gowns are worn over the scrub suit of the operating team during surgical procedures to maintain a sterile surgical field and reduce the risk of transmission of pathogens to both patients and staff. During surgical procedures, the risk of pathogen transmission increases if the barrier materials become wet. Consequently, the multiple- or single-use materials of the drapes and gowns used in a surgical procedure should prevent the penetration of liquids. Reusable materials are typically composed of different tightly-woven textiles and/or knitted cotton, or other fabrics possibly blended with polyester and/or chemically treated. These products have to be durable and provide protection after many cycles of processing and treatment. Disposable surgical drapes and gowns are typically composed of non-woven materials of synthetic and/or natural origin, possibly combined with chemical treatment. ${ }^{26}$ Principles of draping is to isolate dirty from clean, provides an impervious layer, to create a sterile field. Creation of a sterile field is through sterile presentation of the drape and aseptic application technique. If the drape used is not impervious, an additional impervious layer needs to be added, this is area on which authors are aiming.

Because of the number of factors that can contribute to surgical site infections (SSI), experts generally talk in terms of reducing the risk rather than the rate of SSI. It is well recognized that the major microorganisms responsible for SSIs reside on the patient's skin, making preoperative skin preparation and creation of a sterile field/surface a logical approach to risk reduction. In this study, authors have taken a first step in that direction in our hospital with pregnant women undergoing caesarean section. The goal was to measure the incidence of SSIs in post caesarean section patients and effectiveness of this new method.

\section{METHODS}

This study was a prospective case-control study carried out in this study obstetrics and gynecology department of a tertiary care institute from February 2018 to August 2018. All low risk patients, who came to this study casualty and landed up into caesarean section in the course of labour, either primigravida or multigravida were included in this study. All patients, who had previous surgery (obstetrics or non-obstetrics cause), who have comorbidities like hypertension, GDM, chronic medical illness, anemia, obesity etc., were not included in study. Also, the participants who have prolonged leaking per vaginum, prolonged labour trial were excluded. And 
participants who have not given consent for study were not included.

This study was done at GMC hospital Aurangabad of Maharashtra. It's a tertiary care medical college and largest government hospital in this region. Total 18000 deliveries conducted here with caesarean delivery rate $20 \%$ annually. This is little remote area as compare city like Mumbai $(350 \mathrm{~km}$ from Aurangabad). Populations living in this area are mostly belonging to middle class to lower socioeconomic status. Most of the people depend for their living on agricultural activities. Authors chose this study topic to invent a new method to prevent these people from wound infection with poor hygiene condition.

\section{Sample size determination}

The sample size for this case-control study was calculated using the Kish Leslie formula

$\mathrm{n}=\mathrm{z}^{2} \mathrm{pq} / \mathrm{d}^{2}$

Where, $\mathrm{n}$ is the minimum sample size, $\mathrm{z}$ is the standard score corresponding to $5 \%$ level of significance (i.e., 0.05 ), $\mathrm{p}$ is $20 \%$ (the prevalence of wound infection among pregnant women), $\mathrm{q}$ is $80 \%$, and is $5 \%$ confidence limit (the proportion of sampling error).

Authors assumed that the prevalence of wound infection among pregnant women in our hospital was $20 \%$, similar to data obtained from various trial done in past. With an alpha value of $5 \%$ and a precision value of $5 \%$, this study needed 236 participants at least.

\section{Sampling method}

To attain the required sample size within the study timeframe, consecutive sampling was used to recruit participants as follows. Gynae casualty team was informed about study and its purpose. They used to ask the patients complaints, demographic details, socioeconomic status, and obstetrics history, past history. If patient's profile comes into the inclusion criteria, then they explain about study and its purpose. Patients who were willing to participate into the study were included into the study. All the included participants were divided into two groups - case (Double drape technique) and control (Single drape technique). Further management of participants was according to hospital protocol. Detail demographic, obstetrics data collected and saved for future data analysis. Incidences of infection were calculated from numbers of infected wound infection out of total patients.

\section{Participation recruitment and data collection procedure}

Out of these patients, if they landed up into caesarean section, they were recruited into this study according to previously labeled group. Both groups of patients were given same kind of treatment. Patients parts were prepared, clean gown for operation, preoperative antibiotics, Foley's catheterization with no touch technique, preoperative painting of parts after giving the appropriate anesthesia.

In single drape technique (SDT), patient was covered with sterilized draped, then, usual steps of cesarean section were followed like - skin incision, subcutaneous tissue separation, rectus sheath and muscles opened, peritoneum incised, lower segment incision on uterus, delivery of baby, uterus suturing, hemostasis, closure of abdomen in layers in same manor, sterile dressing of wound followed by vaginal toileting with povidone iodine.

But, in double drape technique (DDT), after giving skin incision and before opening the rectus sheath, 2 mops were used above and below the skin incision and attached to edge of incised skin with help of allis forceps or sponge holding forceps to cover all skin, and then, rectus sheath was used to open. Rest technique was same as was in SDT.

Both group patients were received same kind of postoperative treatment. Vitals monitoring, post-operative complication was managed accordingly. Wound checked after 48 hours of surgery and patients were discharged. Suture removal was done on day 8-10 days of surgery. Participants who have healthy wound were advised for further post-natal care of both mother and baby and advised to follow on $30^{\text {th }}$ day of surgery. Participants who have wound infection was advised to get admitted and further management of wound done with daily dressing, antibiotics, vital monitoring; depending on condition of wound.

\section{Statistical analysis}

A statistical software was used to summarize the data authors collected in tables. Continuous descriptive variables were presented as means and standard deviations. At the end, data collected and analyzed with appropriate statistical tests. Since this study data were non- parametrical, so testing was done according to that. Chi square test was used for categorical variables. Results are presented as frequency tables, standard deviation and percentages. Statistical significance was set at $\mathrm{p}<0.05$.

\section{RESULTS}

Maximum numbers of patients were observed in age group of 26-30 years in both the groups. Now this is also the most common age group marriage in India.

Mean of age of all the patients was 28.46 years, whereas mean age for SDT and DDT groups were 28.6 and 28.3 years respectively. By applying t-test for comparing the age among both the group, statistically there was no significant difference. 
Table 1: Distribution of cases according to age of patients.

\begin{tabular}{|lll|lll|}
\hline No. & Age (in years) & $\begin{array}{l}\text { SDP group } \\
\text { Number }\end{array}$ & Percentage & DDP group & Percentage \\
\hline $\mathbf{1}$ & $18-22$ & 12 & 10 & 14 & 11.6 \\
\hline $\mathbf{2}$ & $22-26$ & 22 & 18.3 & 22 & 18.3 \\
\hline $\mathbf{3}$ & $26-30$ & 36 & 30 & 38 & 31.6 \\
\hline $\mathbf{4}$ & $30-34$ & 35 & 29.1 & 33 & 27.5 \\
\hline $\mathbf{5}$ & $>35$ & 15 & 12.5 & 13 & 10.8 \\
\hline Total & & 120 & 100 & 120 & 100 \\
\hline
\end{tabular}

Table 2: Statistics of age of all patients.

\begin{tabular}{|ll|}
\hline No. & $\mathbf{N}=\mathbf{2 4 0}$ \\
\hline Mean & 28.46 \\
\hline Mode & 29 \\
\hline Median & 29 \\
\hline Standard deviation & 2.70 \\
\hline Minimum & 18 \\
\hline Maximum & 35 \\
\hline
\end{tabular}

Maximum numbers of patients were observed in multigravida in both groups. As multiparous is common in our country.

By applying the chi-square test on this data, results showed that, there is no difference in data.
Maximum number of cases were seen in our hospital were among lower and lower middle-class socioeconomic status patients. Upper class socioeconomic status patient usually prefers less crowded hospital which is usual not possible in government hospital.

Total number of cases who were found to be having SSIs was 30, out of 240 patients in this study. So, the incidence of SSI patients in this study is 125 SSIs patients per 1000 low risk caesarean section. Whereas, the incidences of SSI patients in SDT and DDT groups were 183 and 66 respectively, this was this study $1^{\text {st }}$ objective.

More SSI patients were found in SDT as compare to DDT. It means this study technique is better than SDT, but authors have to prove by applying statistical test.

Table 3: Comparison of both the groups according to age.

\begin{tabular}{|llllll|}
\hline & Method & Number & Mean & Standard deviation & P value \\
\multirow{2}{*}{ Age } & SDP & 120 & 28.6 & 2.73 & 0.027 \\
\cline { 2 - 5 } & DDT & 120 & 28.3 & 2.68 & 0.027 \\
\hline
\end{tabular}

Table 4: Distribution of patients according to gravidity.

\begin{tabular}{|llllll|}
\hline & & SDP group & & DDP group \\
\cline { 3 - 7 } & & Number & Percentage & Number & Percentage \\
\hline \multirow{2}{*}{ Gravidity } & Primigravida & 42 & 35 & 45 & 37.5 \\
\cline { 2 - 7 } & multigravida & 78 & 65 & 75 & 62.5 \\
\hline Total & & 120 & 100 & 120 & 100 \\
\hline
\end{tabular}

Table 5: Statistics of gravidity of all patients.

\begin{tabular}{|lll|}
\hline \multirow{3}{*}{ Gravidity } & Chi-square test & Results \\
\cline { 2 - 3 } & $\mathrm{X}^{2}$ & 1.62 \\
\cline { 2 - 3 } & $\mathrm{P}$ value & 0.687 \\
\hline
\end{tabular}

Since this study data is non-parametric, so authors have to use chi-square test for significant of difference of test.
On applying the chi-square test on this study data, $\mathrm{X}^{2}$ 7.46 , with $\mathrm{p}$ value-0.006, it shows that this study results are significant, and difference in data is statistically significant. It means this study new technique DDT (double drape technique) is better than SDT (single drape technique). This was the $2^{\text {nd }}$ objective.

Maximum numbers of cases were seen in 18-22 years in both the groups with $27.2 \%$ and $37.5 \%$ respectively, they were also high in the age group of 26-30 years in SDT 
group. Maximum number of SSI patients was found in young age group.

Mean age of among SSIs patients was 26.1 years, which was lesser than mean of total patients of this study. It means young age population is more prone for SSI infection as compare to mature patients. $\mathrm{P}$ value signifies that, differences in data are significant among the age groups; means SDI group have significant number of more SSIs patients as compare to DDT group.

Table 6: Distribution of patient according to socioeconomic status of patient.

\begin{tabular}{|llllll|}
\hline No. & Socioeconomic status & \multicolumn{1}{c}{ SDP group } & & DDP group & Pumber \\
\cline { 3 - 6 } & Number & Percentage & Numtage \\
\hline $\mathbf{1}$ & Upper & 0 & 0 & 0 & 0 \\
\hline $\mathbf{2}$ & Upper middle & 8 & 6.66 & 7 & 5.9 \\
\hline $\mathbf{3}$ & Lower middle & 28 & 23.3 & 30 & 25 \\
\hline $\mathbf{4}$ & Upper lower & 38 & 31.6 & 36 & 30 \\
\hline $\mathbf{5}$ & Lower & 46 & 38.3 & 47 & 39.1 \\
\hline & Total & 120 & 100 & 120 & 100 \\
\hline
\end{tabular}

Table 7: Distribution of cases according to SSI among both groups.

\begin{tabular}{|llllllll|}
\hline \multirow{2}{*}{ No. } & No. of patients & SDP group & \multicolumn{3}{c|}{ DDP Group } & Total \\
& Number & Percentage & Number & Percentage & Number & Percentage \\
\hline 1. & Total normal patient & 98 & 81.6 & 112 & 93.3 & 210 & 87.5 \\
\hline 2. & Total SSI patient & 22 & 18.4 & 8 & 6.7 & 30 & 12.5 \\
\hline & Total & 120 & 100 & 120 & 100 & 240 & 100 \\
\hline
\end{tabular}

Table 8: Statistics of SSI patients.

\begin{tabular}{|lll|}
\hline \multirow{3}{*}{ SSI patients } & Chi-square test & Results \\
\cline { 2 - 3 } & $\mathrm{X}^{2}$ & 7.46 \\
\cline { 2 - 3 } & $\mathrm{P}$ value & 0.006 \\
\hline
\end{tabular}

Table 9: Distribution of SSI patients according to age in both groups.

\begin{tabular}{|llllll|}
\hline No. & Age & $\begin{array}{l}\text { SDP group } \\
\text { Number }\end{array}$ & Percentage & DDP group & Pumber \\
\hline $\mathbf{1}$ & $18-22$ & 6 & 27.2 & 3 & 37.5 \\
\hline $\mathbf{2}$ & $22-26$ & 4 & 18.1 & 2 & 25 \\
\hline $\mathbf{3}$ & $26-30$ & 6 & 27.2 & 2 & 25 \\
\hline $\mathbf{4}$ & $30-34$ & 4 & 18.1 & 0 & 0 \\
\hline $\mathbf{5}$ & $>35$ & 2 & 9.05 & 1 & 12.5 \\
\hline Total & & 22 & 100 & 8 & 100 \\
\hline
\end{tabular}

Table 10: Statistics of age among the SSI patients.

\begin{tabular}{|ll|}
\hline & $\mathbf{N}=\mathbf{3 0}$ \\
\hline Mean & 26.1 \\
\hline Mode & 22 \\
\hline Median & 26 \\
\hline Standard deviation & 1.36 \\
\hline Minimum & 18 \\
\hline Maximum & 35 \\
\hline
\end{tabular}

$\mathrm{P}$ value showed that that, there is no difference in occurrence of SSI patient in term of gravidity; it means
SSI infection among patients equally seen in both the groups. 
Maximum numbers of cases were seen in lower socioeconomic status patients. Mostly, hygiene is the reason behind this, and which is not seen usually in these groups.

Table 11: Comparison of age in both the groups among SSI patients.

\begin{tabular}{|llllll|}
\hline & Method & Number & Mean & Standard deviation & P value \\
\multirow{2}{*}{ Age } & SDP & 22 & 26.5 & 1.46 & \multirow{2}{*}{0.014} \\
\cline { 2 - 5 } & DDT & 8 & 25.0 & 2.70 & \\
\hline
\end{tabular}

Table 12: distribution of patients according to gravidity.

\begin{tabular}{|c|c|c|c|c|c|}
\hline \multirow{2}{*}{ No. } & \multirow{2}{*}{ Gravidity } & \multicolumn{2}{|c|}{ SDP group } & \multicolumn{2}{|c|}{ DDP group } \\
\hline & & Number & Percentage & Number & Percentage \\
\hline 1 & Primigravida & 14 & 63.7 & 5 & 62.5 \\
\hline 2 & Multigravida & 8 & 36.3 & 3 & 37.5 \\
\hline Total & & 22 & 100 & 8 & 100 \\
\hline
\end{tabular}

Table 13: Statistics of gravidity among SSI patients.

\begin{tabular}{|lll|}
\hline \multirow{3}{*}{ Gravidity } & Chi-square test & Results \\
\cline { 2 - 3 } & $\mathrm{X}^{2}$ & 0.0032 \\
\cline { 2 - 3 } & $\mathrm{P}$ value & 0.954 \\
\hline
\end{tabular}

Table 14: Distribution of patient according to socioeconomic status of patient.

\begin{tabular}{|llllll|}
\hline No. & Socioeconomic status & SDP group & & DDP group \\
& Number & Percentage & Number & Percentage \\
\hline $\mathbf{1}$ & Upper & 0 & 0 & 0 & 0 \\
\hline $\mathbf{3}$ & Upper middle & 1 & 4.5 & 0 & 0 \\
\hline $\mathbf{4}$ & Lower middle & 4 & 18.1 & 1 & 12.5 \\
\hline $\mathbf{5}$ & Upper lower & 5 & 22.7 & 3 & 37.5 \\
\hline & Lower & 12 & 54.5 & 4 & 50 \\
\hline
\end{tabular}

Table 15: Distribution of patient according to treatment received and cured.

\begin{tabular}{|llllll|}
\hline \multirow{2}{*}{ No. } & Treatment & SDP group & \multicolumn{2}{c|}{ DDP group } \\
\cline { 3 - 6 } & Number & Percentage & Number & Percentage \\
\hline 1. & Dressing only & 2 & 9.1 & 1 & 12.5 \\
\hline 2. & Dressing + antibiotics & 2 & 9.1 & 2 & 25 \\
\hline 3. & Re-suturing & 17 & 77.3 & 5 & 62.5 \\
\hline 4. & Re-suturing followed by dressing & 1 & 4.5 & 0 & 0 \\
\hline 5. & Other surgery & 0 & 0 & 0 & 0 \\
\hline & Total & 22 & 100 & 8 & 100 \\
\hline
\end{tabular}

It shows that maximum number of patients in both the groups required resuturing.

\section{DISCUSSION}

The risk for developing SSI has significantly decreased in the last three decades, mainly owing to improvements in hygiene conditions, antibiotic prophylaxis, sterile procedures, and other practices. ${ }^{27,28}$
The incidence ranges from $5 \%$ to $25 \%$ depending on the nature and area of practice. ${ }^{29}$ Hospital based studies from Nigeria reported rates within this range, as compare to these studies; incidence in this study was $12.5 \%$, which is better than studies conducted Nigeria.

According to Vjosa et al study, the mean age of the patients was $31.3 \pm 5.5$ years, with a range from 17 to 46 years. ${ }^{30}$ According to Jasim study mean age for the women was $30.36 \pm 4.8$ (range $=17-45$ ) years. ${ }^{31}$ According 
to a study conducted in Ethiopia, The age of women were ranged 18-43 years with a mean and standard deviation of 28.1 $\pm 5.7 .^{32}$ Whereas, in this study, mean age of patients was 28.46 , which is comparable to these study as range of age in this study was narrower.

According to Jayalaxmi study, $10.6 \%$ cases of primigravida and $6.3 \%$ cases of the multigravida developed wound infection. Primiparous is more prone for wound infection. ${ }^{33}$ In this study primigravida patient were less as compare to multigravida. But SSIs patients were more among the primigravida which may be due to unawareness of labour, lake of education, prolonged trial of labour, and long duration of latent labour in primigravida.

According to Jayalaxmi study, of the 700 cases, 1 out of 30 from socioeconomic status class $3(3.3 \%)$, 9 out of 361 from socioeconomic status class $4(2.5 \%)$ and 47 out of 309 from socioeconomic status class $5(15.2 \%)$ developed wound infection. It is clearly shown that wound infection is common in low socioeconomic status. ${ }^{33}$ Also, in this study, SSIs were more common in lower socioeconomic class patients. It is well known fact that, there is lack hygiene in lower socioeconomic class, which is one of the reasons for more SSIs in this class.

The lack of significant association between nature of surgery (elective or emergency) and wound infection rate may possibly be due to the fact that majority of the surgeries were done by consultants and senior registrars, as poor surgical skills and long operating time are said to contribute more to wound infection. ${ }^{34}$ Same in this study and other part of India, emergency caesareans are performed by resident doctors.

Preoperative preparation is not possible in all cases in gynecology department especially in acute condition like in severe fetal distress, obstructed labour, deep transverse arrest, second stage arrest, ruptured ectopic pregnancy in shock etc., where emergency operation needed in few minutes to save lives of baby and mother. These are some leading indication for caesarean section in our institute. In this situation, preoperative preparation like, preoperative shower, parts shaving, preoperative antibiotics in some cases, preoperative skin preparation with alcohol bases solution, preoperative vaginal toileting in case of prolonged labour were not possible, which are very important steps for prevention of SSIs. Because of this, rate of SSIs in gynecology department can be reduced drastically, if something done to counteract all this and prevent SSIs, like in this study authors used DDT to prevent microbial contamination.

Adhesive plastic incises drapes, plain or impregnated with an antimicrobial agent (mostly an iodophor), are used on the patient's skin after the completion of surgical site preparation. The film adheres to the skin and the surgeon cuts through the skin and the drape itself. ${ }^{35}$ Such a drape is theoretically believed to represent a mechanical and/or microbial barrier to prevent the migration of microorganisms from the skin to the operative site. ${ }^{36}$ However, some reports showed an increased recolonization of the skin following antiseptic preparation underneath adhesive drapes compared to the use of no drapes. ${ }^{37}$

In this technique, authors are using double drape to prevent extra protection to the wound to not infect from commensal and other pathogenic microorganism of skin during caesarean section. Due to long hours of labour, prolong ruptures of membrane, vaginal flora, infected liquor is the source of spread of pathogenic organism to abdominal skin. These pathogenic organisms can be protected by proper using guidelines for prevention of SSIs, which is not possible in most of cases in emergency cases of gynecology. No touch technique like technique which is used in urethral catheterization can also be used for this problem. So, this new technique double drape technique can be used for that.

Two Cochrane reviews regarding early ( $<48$ hours) versus delayed dressing removal and postoperative bathing reported limited data, but no significant difference in SSI rate was shown. ${ }^{38,39}$ Peleg et al conducted a randomized controlled trial comparing postoperative dressing removal at 6 hours $(n=160)$ with dressing removal at 24 hours $(n=160)$ and showed no difference in wound complications. ${ }^{40}$ As compare to this, check dressing was done in this study at 48 hours of caesarean section.

Daily inspection of the cesarean incision is an essential part of the postoperative evaluation. The presence of fever, tenderness, erythema, purulent discharge, or induration should raise a suspicion of infection. ${ }^{41}$ When there are signs of pelvic infection, empirical broadspectrum antibiotic regimen should be initiated, including anaerobic coverage. An acceptable regimen includes clindamycin with an aminoglycoside or aztreonam. For the coverage of Enterococcus, ampicillin may be added to the regimen. ${ }^{42}$ Approximately $90 \%$ of women will be afebrile within 48-72 hours after initiation of antibiotic treatment. Once the women are afebrile and asymptomatic for 24 hours, parenteral antibiotics may be discontinued. If the infection improves with intravenous antibiotics, there is probably no need to follow the intravenous antibiotics with a course of oral antibiotics.

\section{CONCLUSION}

SSI is one of most common complication after caesarean section, and its graph is on increasing trend. It can be prevented by decreasing the caesarean section rate, encouragement for vaginal delivery in primiparous patients and by increasing the rate of vaginal birth after caesarean section. SSI can be prevented by increasing the hygienic condition in laboring patients. It can be prevented by technique used in this study, although this is the first study of its kind, so there will be need for further 
studies to explore the possible contribution to post caesarean wound infection.

\section{ACKNOWLEDGMENTS}

Authors would like to thank Dr. Vijay Kalyankar, Dr. Anurag Sonawane, and Dr. Rupali Gaikwad for being the building lamp in the conduct of this study. Authors also, would like to thank all the faculty members, colleagues and residents, who despite their own engagements were always willing to help for this study.

Funding: No funding sources

Conflict of interest: None declared

Ethical approval: The study was approved by the Institutional Ethics Committee

\section{REFERENCES}

1. Charoenboon C, Srisupundit K, Tongsong T. Rise in cesarean section rate over a 20-year period in a public sector hospital in northern Thailand. Arch Gynecol Obstet. 2013;287(1):47-52.

2. Smaill FM, Grivell RM. Antibiotic prophylaxis versus no prophylaxis for preventing infection after cesarean section. Cochrane Database Syst Rev. 2014;2014(10):1.

3. Miller ES, Hahn K, Grobman WA. Consequences of a primary elective cesarean delivery across the reproductive life. Obstet Gynecol Surv. 2013;68(8):551-2.

4. Molina G, Weiser TG, Lipsitz SR, Esquivel MM, Uribe-Leitz T, Azad T, et al. Relationship between cesarean delivery rate and maternal and neonatal mortality. JAMA. 2015;314(21):2263-70.

5. Ezechi OC, Fasubaa OB DF. Socioeconomic barriers to safe motherhood among booked patients in rural Nigerian communities. J Obs Gynaecol. 2000;20(1):32-4.

6. Onwudiegwu U, Makinde ON, Ezechi OC AA. Decision -caesarean delivery interval in a Nigerian university hospital: Implications for maternal morbidity and mortality. J Obs Gynaecol. 1999;19(1):30-3.

7. Ezechi OC, Nwokoro CA, Kalu BK, Njokanma FO OG. Caesarean section: morbidity and mortality in a private hospital in Lagos Nigeria. Trop $\mathbf{J}$ Obs Gynaecol. 2002;19(2):97-100.

8. Litta P, Vita P, Konishi de Toffoli JOG. Risk factors for complicating infections after cesarean section. Clin Exp Obs Gynecol. 1995;22(1):71-5.

9. Beattie PG, Rings TR, Hunter MF LY. Risk factors for wound infection following caesarean section. Aust N Z J Obs Gynaecol. 1994;34(4):398-402.

10. Hani C, Hospital B. Early discharge from hospital after caesarean section at Chris Hani Baragwanath Hospital. South African J Obstet Gynaecol. 2011;17(1):17-8.

11. Horan TC, Gaynes RP, Martone WJ JW. CDC definitions of nosocomial surgical site infections,
1992: a modification of CDC definitions of surgical wound infections. Infect Control Hosp Epidemiol. 1992;13(10):606-8.

12. Manyahi J. Bacteriological spectrum of postoperative wound infections and their antibiogram in a tertiary hospital, dar es salaam, tanzania bacteriological spectrum of post-operative wound infections and their antibiogram in a tertiary hospital, Dar Es Salaam. Muhimbili Univ Heal Allied Sci. 2012;5(1):15-84.

13. Collier M. Understanding wound inflammation. Nurs Times. 2003;99(25):63-4.

14. Chaim W, Bashiri A, Bar-David J, Shoham-Vardi I, Mazor M. Prevalence and clinical significance of postpartum endometritis and wound infection. Infect Dis Obstet Gynecol. 2000;8(2):77-82.

15. Morhason-Bello IO, Oladokun A, Adedokun BO, Obisesan KA, Ojengbede OA, Okuyemi OO. Determination of post-caesarean wound infection at the University college hospital Ibadan Nigeria. Nigerian J Clin Pract. 2009;12:1-5.

16. Thomas KH. Surgical wound infection, an overview. Am J Med. 1981;70(3):712-8.

17. Jido TA, Uzoho CC DG. Post caesarean wound infection at the Aminu Kano Teaching Hospital Kano. Ann Med Heal Sci Res. 2012;2:33-6.

18. Ogunsola FT, Oduyebo O, Iregbu KC, Coker AO AA. A Review of nosocomial infection at the Lagos university teaching hospital: problems and strategies for improvement. J Niger Infect Control Assoc. 1998;1(1):11-3.

19. Barbut F, Carbonne B, Truchot F, Spielvogel C, Jannet D, Goderel I et al. Surgical site infections after cesarean section: Results of a five -year prospective surveillance. Pan Afr Med J. 2019;8688:1-7.

20. NICE: National institution for health and care excellence. Surgical site infections: prevention and treatment NG125. Clin Guidel. 2019.

21. Tanner J. Tanner J, Norrie P, Melen K. Preoperative hair removal to reduce surgical site infection. Cochrane Database Syst Rev. 2011;11(3):1-3.

22. Anorlu RI, Maholwana B, Hofmeyr GJ. Methods of delivering the placenta at caesarean section. Cochrane Database Syst Rev. 2018:1-93.

23. Atkinson MW, Owen J, Wren A, Hauth JC. The effect of manual removal of the placenta on postcesarean endometritis. Obstet Gynecol. 1996;87(1):99-102.

24. Tuuli MG, Rampersad RM, Carbone JF, Stamilio D, Macones GA, Odibo AO. Staples compared with subcuticular suture for skin closure after cesarean delivery: a systematic review and meta-analysis. Obs Gynecol. 2011;117(3):682-90.

25. Rutala WA, Weber DJ. A review of single-use and reusable gowns and drapes in health care. Infect Control Hosp Epidemiol. 2001;22:248-57.

26. Gibbs RS. Clinical risk factors for puerperal infection. Obs Gynecol. 1980;55(5supply):s178-84. 
27. Krieger Y, Walfisch A, Sheiner E. Surgical site infection following cesarean deliveries: trends and risk factors. J Matern Neonatal Med. 2017;30(1):812.

28. Nice C, Feeney A, Godwin P, Mohanraj M, Edwards A, Baldwin A, et al. A prospective audit of wound infection rates after caesarean section in five West Yorkshire hospitals. J Hosp Infect. 1996;33(1):5561.

29. Chukwudebelu WO. Burst abdomen following caesarean section. Inter J Gynecol Obs. 1978;15(6):532-4.

30. Zejnullahu VA, Zejnullahu VA, Isjanovska R, Sejfija Z. Surgical site infections after cesarean sections at the university clinical center of Kosovo: Rates, microbiological profile and risk factors. BMC Infect Dis. 2019;19(1):1-9.

31. Jasim HH, Sulaiman SAS, Khan AH, Dawood OT, Abdulameer AH, Usha R. Incidence and risk factors of surgical site infection among patients undergoing cesarean section. Clin Med Insights Ther. 2017;9.

32. Azeze GG, Bizuneh AD. Surgical site infection and its associated factors following cesarean section in Ethiopia: a cross - sectional study. BMC Res Notes. 2019;12:1-6.

33. Subramani J, Perumal D. To estimate the incidence, etiology and risk factors of wound infections in women who undergoes cesarean section at Kilpauk Medical College Hospital: a prospective study. Int J Reprod Contraception, Obstet Gynecol. 2017;6(5):1793.

34. Webster J, Alghamdi A. Use of plastic adhesive drapes during surgery for preventing surgical site infection. Cochrane Database Syst Rev. 2015;2015:4.

35. French ML, Eitzen HE RM. The plastic surgical adhesive drape: an evaluation of its efficacy as a microbial barrier. Ann Surg. 1976;184:46-50.
36. Falk-Brynhildsen K, Friberg Ö, Söderquist B, Nilsson UG. Bacterial colonization of the skin following aseptic preoperative preparation and impact of the use of plastic adhesive drapes. Biol Res Nurs. 2013;15(2):242-8.

37. Toon CD, Lusuku C, Ramamoorthy R, Davidson BR, Gurusamy KS. Early versus delayed dressing removal after primary closure of clean and cleancontaminated surgical wounds. Cochrane Database Syst Rev. 2015;2015:9.

38. Owen JAW. Wound complications after cesarean sections. Clin Obs Gynecol. 1994;37(4):842-55.

39. Peleg D, Eberstark E, Warsof SL, Cohen N, Shachar IB. Early wound dressing removal after scheduled cesarean. Am J Obstet Gynecol. 2016;215(3):388.e1388.e5.

40. Fitzwater JL. Prevention and management of caesarean wound infection cesarean surgical site infections wound treatment management. Obstet Gynecol Clin North Am. 2014;41:35249.

41. Duff P. Maternal and perinatal infection-bacterial. In: Gabbe SG, Niebyl JR, Simpson JL et al, editor. Obstetrics Normal and Problem Pregnancies. $6^{\text {th }}$ ed. Philadelphia, PA: Elsevier; 2012:1140-1155.

42. Mackeen AD, Packard RE, Ota E, Speer L. Antibiotic regimens for postpartum endometritis. Cochrane Database Syst Rev. 2015:2.

Cite this article as: Kumar M, Pawar P. Prevention of wound infection: a new technique. Int J Reprod Contracept Obstet Gynecol 2020;9:3645-53. 